\title{
"Benevolence" of Confucianism in the Eyes of Australian High School Teachers
}

\author{
Shi $\mathrm{Li}^{1}$ \\ ${ }^{1}$ School of Arts, University of New England, Australia \\ Correspondence: Shi Li, School of Arts, University of New England, Australia. E-mail: sli7@une.edu.au
}

Received: May 8, 2013 Accepted: August 2, 2013 Online Published: August 30, 2013

doi:10.5539/ass.v9n11p33

URL: http://dx.doi.org/10.5539/ass.v9n11p33

\begin{abstract}
This paper examines empirically the reflections of a group of Australian high school teachers on the core value of the Confucian doctrine 'benevolence', in order to explore Confucianism in contemporary Chinese culture. The data has been collected from the diaries kept by these teachers, all of whom are students at The University of New England, Australia, and participated in an In-country Language Program held in the city of Xi'an in mainland China during January 2011. The paper begins with a brief literature review of Chinese habits in relation to 'benevolence' and provides some details about the In-country Language Program held in Xi'an. It then proceeds to the research aims and questions of this study, followed by a brief review of the concept of culture, Confucianism, and the research methodology employed. Finally some discussion of the group's reflections will be considered and conclusions drawn from the data.
\end{abstract}

Keywords: Confucianism, benevolence, contemporary Chinese culture, Australian high school teachers

\section{Introduction}

A wealth of academic material can be found that has focused on both traditional and contemporary Chinese culture (He, 2006; Hong, 2007; Howard, Begun, Meadows, \& Stroup, 2001; Li, 2001; MacLeod \& MacLeod, 2001; Zou, 2006). Along with books and journal articles, other materials include internet sources such as 'blogs' that offer lengthy debates on the Chinese habits of spitting in public places, pushing and shoving to get on and off public transport and the lack of words like 'thank you', 'excuse me', 'I'm sorry' that are regarded as a common courtesy and a sign of good manners. This lack of so-called 'social graces' has often received negative media responses, both in China and abroad, and is considered as loss of national face by Chinese travel agencies and many Chinese. The breadth of literature reviewed for this paper indicates that to-date no research has been conducted that relates these habits to Chinese culture or to the tradition of Confucian doctrines. Is such behaviour as spitting in public, lack of consideration by drivers for pedestrians at crossings, and a lack of common courtesy by many in the public domain a cultural norm? And to what extent has Confucianism remained as a resilient cultural tradition, one that encourages people to adopt the philosophy of 'doing unto others as you would like them to do unto you'?

Due to a lack of earlier historical records, the negative social behaviour in Chinese society can first be traced back to the early 1900s, at which time the father of China, Sun Yat-sen, criticized the habit of spitting (1924). However, this habit has remained commonplace to the present day. After the establishment of the People's Republic of China in 1949, the governments at national, regional and local levels initiated a number of campaigns to curb the habit of spitting in public places. For example, following the outbreak of SARS in 2003 and during the lead-up to the 2008 Beijing Olympic Games occasions when world media was focused on China. The use of media advertisements to re-educate the behaviour of people were prevalent during these times, and today signage such as 'no spitting' is prominently on display in all Chinese cities. However, these negative patterns of behaviour in much of the Chinese population can still be observed.

During January 2011, a group of 13 students from The University of New England, Australia participated in an In-country Language Program held in Xi'an in mainland China. All of these participants were qualified high school teachers. For part of their assessment they were required to keep reflective diaries about the behaviour of Chinese people they observed and had interaction with, during their three week stay - both at the university and in the public domain. In particular, they were required to reflect on two of the five constant human virtues of Confucianism, 'benevolence' and 'propriety'. The purpose of this assessment task was for them to reflect on 
their experiences with Chinese people, and to consider to what extent these two values of Confucianism, 'benevolence', in particular, the primary value of Confucianism, continue to form a resilient Chinese cultural tradition in modern day China.

\section{Research Aim and Questions}

This paper aims to examine empirically the reflections of a group of Australian high school teachers on the core value of Confucian doctrine, 'benevolence', in order to explore Confucianism in contemporary Chinese culture.

To analyse the material from the teachers' diaries, the theoretical hypothesis is proposed: The bad habits of Chinese people are related to the 'benevolence' of Confucianism. Drawing on discourse theory, the examination of the descriptions and reflections of the participating teachers, in relation to the above values of Confucianism, sought answers to the following three research questions:

1) How did the teachers describe their findings of 'benevolence' and 'propriety' in Chinese people?

2) How did the teachers reflect on Confucianism as a resilient Chinese cultural tradition?

3) What was the overall impression they had formed about Chinese people?

\section{The Concept of Culture and Confucian Doctrines}

Before relating habits to culture, more specifically Confucian doctrines, it is worthwhile to first look at how culture and Confucianism is defined. The term 'culture' is complex and multidimensional and it includes the traditions, religious and other beliefs of a society that form a particular way of life, which in turn leads to national differences. However the definitions of 'culture' have failed to reach any concerted agreement amongst academics. For example, Kroeber and Kluckhohn (1952) identified over 160 different definitions of 'culture'; the British scholar, Chris Brown (2000) asserts that 'culture' is a highly contested term while Reeves (2004) firmly believes that very few writers in international relations, even today, have given an adequate definition of this contentious term. Among the definitions, in general, the anthropological view of culture is one of the most acceptable concepts at the fundamental level (Bull, 1977; Morgenthau, 1962; Reeves, 2004; Tylor, 1871/1903). Margaret Mead claimed that ' $(w)$ e are our culture'... and it is 'not blood, but upbringing which determines all of ... [our] way of behaving (1942/1943, pp. 20,21)' Thus, in this sense, 'culture' is defined as the way of behaving, the specific attributes of the community or country. The distinctiveness of the anthropological view of 'culture' provides a concept of essentialist ontology, in which the essence of culture makes and keeps Chinese people, Chinese, and this inherent Chinese-ness is rooted in their own community.

However, culture is also in an active process of change that occurs under a wide range of influences, and the reality of social life is constantly in a state of flux. As Reeves (2004, p. 71) points out, "societies have always been open to artefacts and ideas from outside", hence cultural values are changing all the time. Therefore, culture is not static but dynamic, and it goes hand-in-hand with economic and social changes. Since the market economy reforms in China during the early 1980s, its economy has been increasingly integrated into the global economy. Schools of western thought such as materialism and consumerism, have also been introduced to China, and been rapidly accepted by the younger generations, which has not only had a phenomenal influence on the lifestyle of the Chinese population, but also on their way of thinking. The internal diversity of a culture is another aspect that should be noted for as George Hunt pointed out 'one cannot find two Indians who tell a story alike (cited in Stocking Jr., 1996). These differences within a given culture could be those of class, education, politics, gender, religion, and also between geographical regions of a country that may have their own dialects and localised customs.

Compared to the variables in the definitions of 'culture', it is well recognised that Confucianism forms the core value of Chinese traditional culture. Confucianism is a set of moral and ethical norms, a means by which to measure and discipline people's behaviour. Five Constant Virtues are widely regarded as the core values of Confucianism: 'benevolence' (humanity), righteousness, propriety, wisdom and faithfulness (Ch'en, 1986). 'Benevolence' is equated with humanity, the core value of the Confucius doctrines that teach "don't do to others what you would not like yourself'. That is to say, 'benevolence' is a kind of universal kindness, the quality of being warm-hearted, considerate and sympathetic. As Guo (2004) stresses that underlying all these values is the central concept of humaneness (benevolence). Such is the primacy of humaneness in the Confucian conception that it is the summation of all virtues. 'Propriety' is politeness, reflecting the manners that are the results of 'Ren' or 'Benevolence'. In other words, 'propriety' is only the representational form of 'benevolence', for it is 'benevolence' that functions as the guiding principle of 'propriety'. If a person has 'benevolence', he or she will naturally present themselves in a proper manner. If a person lacks 'benevolence', it follows that courteous behaviour by this individual should not be expected. Of course, some extra effort needs to be made to learn the 
rituals for 'propriety' if 'benevolence' is possessed; however, a person who has no rituals and proper behaviour cannot gain a high level of' benevolence'. Accordingly, although teachers were required to comment on the two elements, 'benevolence' and 'propriety', the former provided the key factor for their observations and reflections.

\section{Research Methodology}

As mentioned earlier, the participants in this study were students from The University of New England in Australia. Prior to their departure for China, the 13 students enrolled in the In-country Language Program were advised that as an assessment task they would be required to write three reflective diary entries on two core elements of Confucianism ('benevolence' and 'propriety'), based on their observations, and interactions, with Chinese people. The total number of words required for these diary entries was approximately 1500 , but no specific word length was stipulated for each entry. The students were expected to address the two following questions:

1) From the students' personal observations while in Xi'an, do these two elements of Confucianism manifest themselves in people's behaviour in contemporary Chinese culture?

2) How did each of them reflect on the contemporary Chinese culture they experienced?

Out of a total of 13 students, 11 of them gave permission for the reflective material in their diaries to be used in this paper. Accordingly, this study involves the work of 11 student participants. In general, qualitative research consists of small sampling units studied in depth. For as Wolcott (1994) stresses, a large sample in qualitative research does not enhance the research; indeed, it can do the opposite as it might lack the depth and richness of a smaller sample. Although Patton (1990) believes that no guidelines exist for sample size in qualitative research, it is quite common that for a homogeneous group, 6-8 data units are necessary (Kuzel, 1999). Therefore, I believe that the size of sampling researched for this paper is more than adequate for the purposes of this study.

To enhance the validity of the research and help to rule out the influence of biases and inequivalence, an evaluation of contextual factors is necessary. In this paper, contextual factors involve such characteristics of the participants as their socioeconomic status, education, age and cultural background. All the participants in the study grew up in Australia, 10 have European ancestry and 1 has South Korean ancestry. None of the 11 participants had any Chinese language background. They were all employed as high school teachers by the NSW Department of Education and Training, and have completed tertiary studies to at least bachelor level. The group consisted of five males and six females with ages ranging from the late twenties to early fifties. They have all been brought up and educated in western culture in the developed nation of Australia. The names of all consenting participants have been replaced by pseudonyms to ensure anonymity. Five of the teachers - Eric, Jasmine, Richard, Vincent and Bret - had previously travelled to China, and only Joan, who happens to have an old friend in Xi'an, had not travelled to China before. For all of the participants English is their primary language, but some elementary level of Chinese language had been obtained during one year of study at The University of New England, Australia. To minimise the influence of the researcher, who is the participating students' lecturer in Chinese language at The University of New England, no induction or information session for cultural shock was held prior to the groups' departure for China.

An empirical method is employed in this study. Three constructs have been identified in the process of analysis: habits, 'benevolence', and Confucianism. Two independent variables are habits and 'benevolence', and two dependent variables are 'benevolence' and Confucianism. These constructs form two relations between habits and 'benevolence', 'benevolence' and Confucianism. The latter as dependent variable is dependent on the former of independent variable for each relation. The causal relations of these constructs are presented as habits giving rise to (non-) existence of 'benevolence', and (non-) existence of 'benevolence' leading to (a loss of) Confucianism in Chinese culture. The present study links these constructs and empirically examined the relations between habits, 'benevolence' and Confucianism.

A qualitative research method has been used in this study for in-depth interpretation of the teachers' reflections on the behaviour of Chinese people. Denzin and Lincoln claim that qualitative research 'stress[es] the socially constructed nature of reality' (2003, p. 13). The qualitative method is 'like the nets of deep-sea explorers, qualitative studies may pull up unexpected and striking things for us to gaze on' (Barton \& Lazarsfield, 1969, p. 166). The strength of the qualitative method is that it enables the researcher to gain an insider's view of the field on account of close association with both the participants and their activities within the setting. It is also the belief of this researcher that 'reality is not something "out there", independent of people' (Becvar, Canfield, \& Becvar, 1997, p. 3), and that 'observations are not made from a blank slate that is value-and concept-free. Rather, people observe with preconceptions that are guided by values' (Becvar, et al., 1997, p. 16). Also as Gale notes, 
'knowledge is actively constructed by the individual and not passively received' (1995, p. 13). Thus, a constructivism view is held in this study to consider the reflections of these teachers, constructed during their time in China, which might have been coloured by their own differently held personal values developed through their upbringing. However, the focus of this study is not about the participants' preconceptions or misconceptions but their reflections on contemporary Chinese that they observed first hand during their time in Xi'an.

\section{Data Analysis}

To answer the first research questions: How did the teachers describe their findings of 'benevolence' and 'propriety' in Chinese people, the excerpts of the teachers' reflections are presented in a top-down analysis, due to the nature of the study that all the observations were clearly required to focus on 'benevolence' and 'propriety'. The reflections of the teachers on these core aspects of Confucianism were mostly found to focus on the habits of Chinese people. As 'benevolence' is the underlying source of 'propriety', or to some extent that 'propriety' is the representation of 'benevolence', all the descriptions on 'propriety 'are directed to 'benevolence'. The following is an analysis based on codes for habits, 'benevolence', and Confucianism; codes appear in bold and are italicised, representing one of the two relations of habit-'benevolence' and 'benevolence'-Confucianism.

The observations of the participants were found to focus mainly around the two aspects of consideration for strangers and for people in some form of relationship or friendship that have been easily identified by the researcher. For example, lack of consideration for strangers includes such behaviour as spitting, courtesy in public areas, in particular, pushing and shoving to get on and off buses. Each of these aspects is summarized with some relevant excerpts of the descriptions that the teachers made, followed by their reflections on these aspects of behaviour to see how they cognized their interactions with Chinese people.

Little consideration was accorded to strangers or to serving staff in restaurants for Jasmine and Emma. Jasmine, who had also been to China one year before the study, observed that "it is not a common occurrence to [hear] people say 'thank-you', 'please', or 'sorry' when asking for something, receiving something, or [after] being offensive". She further commented that "In China you are looked upon as slightly odd when you say 'please' and 'thank-you' ... It is a similar experience when you are bumped into in the street or subway there is no sorry." And what happened to Emma on the plane made her very upset:

"[T] he (Chinese) gentleman sitting next to me on the plane who couldn't wait long enough for me to move out of the way to open the overhead lockers and gave me a right solid whack as he rushed to get his bags to get out of the plane. No apology either at any stage. The plane hadn't even stopped taxiing and everyone was up, seat belts were off, mobile phones were turned on."

Unfriendly, unhelpful and impatient service was also experienced at restaurants, hotels and shops, and even during flights on the plane. In restaurants, Jasmine "saw a customer ignore the presence of a waiter who had brought him something". Vincent was refused help with finding a safe that was said in the hotel room. Nicole was ignored by a hotel receptionist of her request for an adaptor, which was said to offer in English information. Vincent wrote that:

Waiters also begrudgingly served us. Shop assistants are not in such bad moods but generally unpleasant... Even a number of flight attendants on more than one flight (Air China \& China Eastern) were disinterested. I feel that they are tired of the mostly Chinese passengers who were being demanding. They are coping by being strong and detached.

However, a good number of the acts of kindness were also spotted by 7 teacher participants. "In the supermarkets and most small shops, the assistants were delightful, helpful, engaging" (Barbara). The "educated (people) on campus have been warm towards me. We have even shared jokes and a cigarette...even though I don't smoke! An old lady offered me her seat on a crowded bus" (Vincent). "[P]eople in small shops and stalls (not including the tourist markets near the Bell Tower) were much friendlier and helpful', said Nicole. She continued that she could not forget how a young [Chinese] man helped them to find the right bus. But, especially, she was impressed by the day spent climbing Huashan Mountain:

The best day I had in China was the day we went climbing Huashan (Mountain). We passed many people who said hello, welcomed us to Shaanxi, said "jia yo (English translation: go, go)" to encourage us and exchanged sympathetic looks as we puffed and panted our way up the thousands of stairs! ...As it became late afternoon a few people (men) looked concerned that we were still climbing and indicated that we needed to return to the cable car. I found this very kind hearted (benevolent) of them.

Furthermore, four other participants also reflected on witnessing acts of kindness. Jack "saw a young man move 
over quickly to [a] homeless man and pass to him a neatly wrapped takeaway meal in a plastic bag". Kate noted "a bunch of RMB notes in the beggar's hand, I realised the good-willed- nature of many people still exists". Eric was also "the recipient of very good manners... a stranger taking my passport in care with great effort to get it back to me" at Xi'an airport. Joan was impressed by a young Chinese girl who helped her with a one Yuan bus fare.

Spitting in public drew the most negative reflections from three teachers, Vincent, Nicole and Barbara. Vincent stated that "we have found the loud clearing of one's throat and spitting on the footpath horrific"! Nicole noted that this 'horrific' behaviour happened everywhere in the streets. 'It is quite confronting for us Australians to see men and sometimes women doing this (clearing of the nose and throat by spitting on the ground) all around us here in the streets of Xi'an." Barbara noticed during a bus trip to the airport that even the bus driver "smoked continually and spat phlegm out of the bus window as he was driving." She further reflected on this habit:

[I]t was a matter of course to roll phlegm up from the pit of "wherever" to artfully lob spit-balls of bacteria-ridden phlegm onto the pavement into the path of unsuspecting passers-by. A cultural more, apparently, but so at-odds with the need to have little negative effect on others so life can be harmonious.

Little consideration for others was also pointed out in chaotic and frightening traffic by Eric, Jack and Nicole. "The traffic seemed chaotic with no rules and all manner of vehicles pushing their way into central Xian" (Eric). "There were many instances witnessed by the teachers in which a car or bus or bicycle would cut in front of or block the path of another vehicle forcing it to change lanes or to even stop its full motion" (Jack). Nicole said: "[t]he traffic itself is chaotic and you take your life in your hands when you cross the road as a pedestrian whether or not you use the "crossings". They argued that drivers could be pedestrians when they do not drive and further questioned how they could do unto others what they would not want others do unto them.

Pushing on buses and few people giving up their seats to the elderly was referred to by seven teachers, Nicole, Richard, Vincent, Jasmine, Barbara, Eric, and Kate:

When the bus stopped people pushed and shoved to get onto the bus and lines and order were a nonexistent entity, benevolence seemed absent in this situation as the quick outmanoeuvred the old and the very young were pushed out of the way...Getting off the bus was also an exercise in pushing and shoving and if someone was standing in the doorway they would not move to the side to allow passengers to exit (Nicole).

"Pushing in and not queuing is bothersome" (Vincent). People sometimes lined up for buses yet not necessarily in an orderly fashion, but when the bus actually arrived, Barbara found that "then all niceties were discarded as the masses lost all sense of 'propriety', 'jumping the queue' and pushing dangerously forward, forcing all in front of them towards the bus...it is "an intimidating, terrifying process". While for Nicole, it also meant bruises: "I was pushed on the bus, pushed down the bus and off the bus! I literally had bruises from being pushed against steps in the bus. People run to get on the bus and if you don't force your way you don't get on." Regarding giving up seats to the elderly, Nicole "saw some people getting up to give their seat to the elderly but it did not always happen. One very small old lady was being squashed between other passengers and no one took any notice let alone gave her a seat"! Richard reflected that:

There appeared to be no benevolence shown toward others in the "getting on the bus process" and once on board the young did not offer their seat to the older passengers, though I did once see a younger person rise and offer his seat. The young often played the "I am looking at my phone so I can't see you standing there" game and no one talked to anyone else on the bus.

However, in terms of Chinese people's attitude towards people in some form of relationship or friendship, it seems to be a completely different story. Kate noticed that "[f]rom personal observation people's actions of kindness or care remained mostly within their own family or friendship circle." This perception was confirmed by two other teachers: Joan, who had an old friend in Xi'an, and Bret, who had travelled to China several times in the past. This kindness can also be extended to other forms of social connections, as Joan and Bret concurred that such kindness was strongly apparent and reciprocal between the students and their teachers, and between the host and the guest. Jasmine observed that "all of the tour guides, teacher students and the shopkeepers around Xian Normal University were very friendly and willing to help with anything." Bret noted the prevalence of "Guanxi - the idea of creating relationships to create a mutual beneficial outcome for all involved". In the above views, relationship, or Guanxi, is the key in regard to any positive social interaction in which kindness can be observed. Yet, obviously this kind of friendship or relationships was not experienced and shared by most of the group who had not travelled to China before or not often.

Discussion, conclusion and implications 
As stated by Becvar, et al (1997): 'people observe with preconceptions that are guided by values'. Despite the fact that the participating group of Australian high school teachers all shared a similar social, cultural and educational background, the preconceptions they held have been shown to a varying degree due to their different family backgrounds, personal experiences and even their individual personalities. It is clear that these variables within the participants, in turn, had an effect on the approaches each of them adopted and the reflections they made on the Chinese people they observed and interacted with during their time in Xi'an. There is no denying that there could have been some misconceptions or even prejudice in their reflections.

To address the second research question: how did the teachers reflect on Confucianism as a resilient Chinese cultural tradition, besides the view of inappropriateness to make judgmental comments on another culture expressed by Nicole, the reflections of the other 10 participants presented three points of view on existence of "benevolence": somewhat lack (5 teachers), yes but in relatives and friends ( 2 teachers), and a complete loss (3 teachers).

Despite having witnessed some acts of 'benevolence', five of the participating group hold the view that benevolence has been lost or retained to some extent, just as Richard writes: "in my opinion, China [has] deviated from Confucius teaching in many areas". Seeing "a bunch of RMB notes in the beggar's hand" also did not override Kate's judgement that "modern day China had in some cases 'outgrown' some of these traditional values... I feel that its people should take a step back and try to recover some of the good teachings and social morals that Confucianism once upheld". Eric, who had already been to China several times and nearly lost his passport at Xi'an Airport on this trip, said that "[ $\mathrm{t}] \mathrm{he}$ Confucian values either seem to have endured by teaching or through their simple common-sense merits are still as relevant and demonstrated in contemporary China today". Yet, in his diary entries he reflected more on the chaotic traffic and the way people push and shove each other on the buses, and in turn, he raised the question: "[w]ere people treating each other the way they would like to be treated, as taught by Confucius?" Whereas for Barbara and Jack, having experienced some acts of kindness and some unpleasant social graces, they seemed to have found 'harmony' in China's society. Jack witnessed no ire in chaotic traffic and pushing and shoving on buses, and convinced himself that this is the "notion of "keeping the peace' to 'live in harmony"'. His view coincidentally concurred with Barbara, as stated:"harmony existed in the midst of what could be seen as chaos."

The reflections of Bret and Joan clearly indicate that 'benevolence' exists in China among people in some form of relationship. Bret, who had travelled to China several times in the past, reflected that "[t]o begin with, the enormity of China can at first seem daunting", but once having created "relationships to create a mutual beneficial outcome for all involved", then "[f]or me personally, the China Xi'an experience has been truly memorable and thought-provoking". As he concluded, 'benevolence' exits in modern China but with the condition that it is in some form of relationship or friendship. Rather than expected to reflect on both the pros and cons of Chinese culture, Joan, who was reunited with an old friend while in Xi'an, recorded no negative comments on Chinese culture, while negative social behaviour was quite dominating in the reflections of other teacher participants. This could suggest that Joan might be seeking to avoid offence to her lecturer, a Chinese ethnic, or that she was overwhelmed by her friend's hospitality and the warm-hearted offer by a young girl, a stranger, to pay her bus fare.

The point of view of a complete loss of 'benevolence' is strongly expressed by three participants. Despite the observations and experiences of warm interaction with people on campus, and an old lady giving up her seat on a crowded bus, Vincent still came to his conclusion that "[o]n the whole the Chinese give the impression of being rude and noisy. This isn't conforming to the expectations of 'propriety' and 'benevolence". He went even further to say that "Chinese society is very 'dog eat dog', it is a 'survival of the fittest and competitive", while Emma and Jasmine recorded no positive experiences of 'benevolence' in Chinese people. In particular, Jasmine, although she admitted that "[p]erhaps this perceived lack of manners is simply a way of dealing with the realities of living in a crowded society that at times lacks the resources to deal with population's demands", made a harsh remark: "at face value it would appear that the Chinese people do not hold to Confucianism beliefs... the Chinese are a rude race".

Guo (2004) asserts "an unwavering conviction that China has strayed from its own natural path, as a result of a century of revolutions- the communist revolution in particular - and of modernization, or Westernization, and that the nation has consequently suffered inner degeneration." The contemporary Chinese culture appears to be a mix of traditional culture, communist ideology and western values. The traditional Chinese culture encompasses diverse schools of thought, including Confucianism, Taoism and Buddhism. Nevertheless, Confucianism is undisputedly the accredited philosophy that forms the foundation of the Chinese cultural tradition theoretically. Of its values, 'Ren' or 'benevolence' is at the core. 
What was the overall impression the group formed about Chinese people? 'Ren' or 'benevolence' is as often said: 'do unto others as you would be like to have done unto you'. Would Chinese spit at home? Would they like to be treated indifferently by servicemen or strangers who offend them? Would aggressive and indifferent drivers wish to be treated as they treat pedestrians? As noted by Ann Stevenson-Yang (sited from Li, 2001), a veteran observer of Chinese society, foreign visitors might be impressed by private hospitality but are often shocked by the prevalence of public discourtesy and indifference by Chinese to strangers. Many Chinese people are not considerate of others and appear to have lost the sense of 'benevolence', which forms the core value of Confucianism. In the reflections of the 11 teachers whose diary entries provided the research material for this paper, 7 explicitly presented their observations and reflections that indicate benevolent practice in Confucianism in existence in the contemporary Chinese culture, but seriously jeopardized, but 3 formed the strong view that there was no 'benevolence' in Confucianism in existence in contemporary China. If not to take into consideration possible superiority or prejudice that some participants might have held, there has been sufficient evidence to demonstrate that Confucianism is seriously sick but not deceased in China's society (Tang, Mou, Xu, \& Zhang, 1958). The research outcome also echoes to the New Confucians' call for moral regeneration that is based on a perception of escalating moral degeneration in the last two decades (Guo, 2004). When looking at the causal relations of the three constructs of habits, 'benevolence' and Confucianism, it is clear that the 'bad habits' of Chinese people, are bringing about a lack of 'benevolence' which, in turn, undermines the resilience of Confucianism as an on-going cultural tradition.

The research outcome clearly indicates that it is imperative to rejuvenate "benevolence", the core value of Confucianism in China and its people. It was very necessary that in the last two decades the central government initiated a Confucian revival campaign by the introduction of Confucianism in the school curriculum across the country in an effort to encourage "the perfection of personality through the identification with, and the practice of, these Confucian virtues cherished by the community (Guo, 2004, p. 83)". It also indicates that this would be a long-term, demanding and challenging task for Chinese government and Chinese people.

The research results for this paper are not exhaustive, and the limitations of these results are threefold. Firstly, the research findings rest only from qualitative research methods, due to the fact that no prior research data is available that can offer an indication of what percentage of Chinese people have these bad habits. Secondly, the teachers' reflections did not take into account the internal diversity of a culture, such as the differences between geographical regions in China (e.g. South versus North) and in the social status of the people observed. It must be pointed out that not all Chinese people are responsible for perpetuating these negative types of behaviour. As noted by Hofstede (1984) not all members of a social group will hold exactly the same features, and I'm aware that the generalizing of Chinese 'bad habits' in this study could be unfair and offensive to some, and I apologise for this. Lastly, social-economic differences at both national and personal levels might have generated some misconceptions and even prejudice for these participants, which in turn coloured their observations and reflections to some extent. Nevertheless, this study provides a further exploration of contemporary Chinese culture, and addresses some of the ways in which the cultural tradition of Confucianism has been affected, as contemporary Chinese society comes to terms with a variety of conflicting influences from across the world.

\section{References}

Barton, A., \& Lazarsfield, P. (1969). Some functions of qualitative analysis. In G. Macall \& J. Simmons (Eds.). Issues in Participant Observation. Reading: Addison-Wesley.

Becvar, R. J., Canfield, B. S., \& Becvar, D. S. (1997). Group work: cybernetic, constructivist, and social constructionist perspectives. Denver: Love Publishing Company.

Brown, C. (2000). Cultural Diversity and International Political Theory: from the Requirement to "Mutual Respect"? Review of International Studies, 6(2), 15.

Bull, H. (1977). The Anarchical Society: A Study of Order in World Politics (2nd ed.). Basingstoke and London: Macmillan Press Ltd.

Ch'en, C. (1986). Neo-Confucian terms explained. New York: Columbia University Press.

Denzin, N., \& Lincoln, Y. S. (2003). The discipline and practice of qualitative research. In N. K. Denzin \& Y. S. Lincoln (Eds.), Strategies of Qualitative Inquiry (2nd ed.). California: Sage Publications, Inc.

Gale, J., \& Long, J. (1995). Theoretical foundations of family therapy. University of Georgia.

Guo, Y. (2004). Cultural Nationalism in Contemporary China. London: Routledge. 
He, F. (2006, May 5). China Focus: Chinese tourists urged to get rid of bad habits. Xinhua News Agency, 1. Retrieved from http://search.proquest.com.ezproxy.une.edu.au/docview/452533973?accountid=17227

Hong, L. (2007, May 7). Correcting bad habits of local tourists. China Daily, 3. Retrieved from http://search.proquest.com.ezproxy.une.edu.au/docview/258039386? accountid=17227

Howard, L., Begun, B., Meadows, S., \& Stroup, K. (2001). Spit happens. Newsweek, 137(14), 1.

Kroeber, A. L., \& Kluckhohn, C. (1952). Culture: a Critical Review of Concepts and Definitions. the Peabody Museum of American Archaelogy, 47(1).

Kuzel, A. J. (1999). Sampling in qualitative inquiry. In B. Crabtrree \& M. Miller (Eds.), Doing Qualitative Research (2nd ed.), 33-45. Thousand Oaks, CA: Sage Publlications.

Li, C. (2001, July 22). Spit and polish for capital's bad habits. South China Morning Post, 1. Retrieved from http://search.proquest.com.ezproxy.une.edu.au/docview/265661372?accountid=17227

MacLeod, C., \& MacLeod, L. (2001, March 6). Reformed spitter says Chinese habit hard to swallow. Washington Times, $15 . \quad$ Retrieved from http://search.proquest.com.ezproxy.une.edu.au/docview/409733751?accountid=17227

Mead, M. (1942/1943). And Keep Your Powder Dry: An Anthropologist Looks at America. New York: William Morrow \& Company.

Morgenthau, H. J. (1962). Politics Among Nations: The Struggle for Power and Peace (3rd ed.). New York: Alfred A, Knopf.

Patton, M. Q. (1990). Qualitative Evaluation and Research Methods (2nd ed.). Newbury Park, CA: Sage Publications, Inc.

Reeves, J. (2004). Culture and international relations (1st ed.). Abingdon, Oxfordshire: Routledge.

Stocking Jr., G. W. (1996). Volksgeist as Method and Ethic. Essay on Boasian Ethnography and the German Anthropological Tradition. Madison, Wisconsin: University of Wisconsin Press.

Tang, J., Mou, Z., Xu, F., \& Zhang, J. (1958). A Manifesto on Chinese Culture to the World. Hong Kong.

Tylor, E. B. (1871/1903). Primitive Culture: Researches into the Development of Mythology, Philosophy, Religion, Language, Art and Custom (Vol. 1). London: John Murray.

Wolcott, H. F. (1994). Transforming qualitative data: Description, analysis, and interpretation. Thousand Oaks, CA: Sage.

Zou, H. (2006, August 25). Bad habits can \& should be changed. China Daily, 4. Retrieved from http://search.proquest.com.ezproxy.une.edu.au/docview/257989067?accountid=17227

\section{Copyrights}

Copyright for this article is retained by the author(s), with first publication rights granted to the journal.

This is an open-access article distributed under the terms and conditions of the Creative Commons Attribution license (http://creativecommons.org/licenses/by/3.0/). 